\title{
Conservação de energia elétrica: conceitos e experiências
}

\section{MOZART VITOR SERRA}

Superintendente de Racionalização Energética da LIGHT. M.A. em Economia e CPhD em Planejamento pela Universidade da Califórnia, Berkeley Foi chefe da Área de Estudos e Pesquisas da LIGHT.

\section{Introdução}

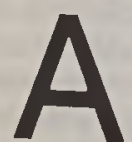
identificação da "conservação de energia" como um recurso energético adicional e possivelmente expressivo surgiu na década de 70 , com a chamada crise de petróleo, nos paises fortemente consumidores deste recurso. Mais recentemente, e sobretudo nos EUA, como resultado das crescentes dificuldades econòmicofinanceiras por que passam as concessionárias americanas, a consideração do aproveitamento concreto deste recurso passou a fazer parte integrante dos planos, programas e projetos destas empresas (Businesweek, 1984). No B rasil, não se pode falar da existência de uma política de conservação, com exceção de algumas poucas iniciativas individuais bem sucedidas em alquns setores da economia.

No caso particular do setor elétrico, a própria idéia de conservação só recentemente começou a tomar corpo. Isto porque parece prevalecer um conjunto de idéias, todas elas desfavoráveis à preocupação com a conservação de energia elétrica, que consideram que, por um lado, como a eletricidade no Brasil é majoritáriamente de origem hidráulica, produzida em território nacional, e, por outro lado, como o consumo per capita de energia elétrica aparece como muito baixo comparado ao de outros países, a eletricidade estaria sujeita a critérios especiais de aproveitamento. Dentre estes estaria o uso preferencial em relação a outros energéticos, à expansão do atendimento sem consideração da qualificacão das características de quem solicita, e à garantia de autonomia energética global a qualquer custo (a qual levaria à substituição de derivados por energia elétrica).
No entanto, recentemente, na presença da realização de obras cada vez mais caras e dada a dificuldade e aos altos custos incorridos na captação de recursos para financiá-las, começa a se observar uma busca por alternativas que envolvam o controle do crescimento da demanda por energia elétrica.

Neste trabalho, procura-se argumentar que:

1. oportunidades de conservação decorrem tanto de modificaçōes na composiçāo do fluxo de bens e serviços e na forma com que estes são produzidos, quanto da obtenção de maiores níveis de eficiência nas transformações entre as formas de energia;

2. alterações nos sistemas de preço, a curto prazo, induzem a substituição de energia por outros insumos à produção, por si só ocasionando a conservação de energia. No caso de alguns bens e serviços, as alterações de preço de energéticos podem levar a modificaçōes nos seus padrões de demanda;

3. a longo prazo, a viabilidade da conservaçāo está intimamente vinculada tanto à ocorrência de mudança tecnológica, que por sua vez pode ser estimulado pelas alterações de preços, quanto às tax as de crescimento da economia;

4. o consumidor nem sempre reage às oportunidades de conservação, quando estas existem, como conseqüência de fathas de mercado. No Brasil, estas oportunidades não estão presentes no mercado em escala significativa e, por outro lado, os preços baixos de energia elétrica dificultam tanto o aproveitamento daquelas oportunidades existentes quanto o surgimento de novas oportunidades;

5. a concessionária, monopólio natural regulado, pode atender ao crescimento da demanda sem ampliar a oferta de energia final, ao adotar medidas de conservação, a um custo médio inferior àquele que vigoraria caso se viesse a garantir capacidade adicional, desta maneira beneficiando a todos os consumidores. O princípio da inexistência de perdedores especifica com base em critérios de eqüidade, a quantidade de recursos a serem alocados a um programa de conservaçäo:

6. a expansão do sistema elétrico segundo critérios de custos mínimos deve formalizar a participação do potencial de conservação em modelos globais de oferta:

7. os instrumentos a serem utilizados na implantaçāo de uma política de conservação podem se basear, quer na manipulação do sistema de preços, na substituição deste por mecanismos centralizados de alocação de recursos ou, ainda, em medidas para corrigir falhas de mercado.

\section{Oportunidades de conservação}

\subsection{Oportunidades de conservacõo: as oportunidades materiais}

As atividades de produção, quer sejam para o mercado, quer sejam domés-

\section{FIGURA 1}

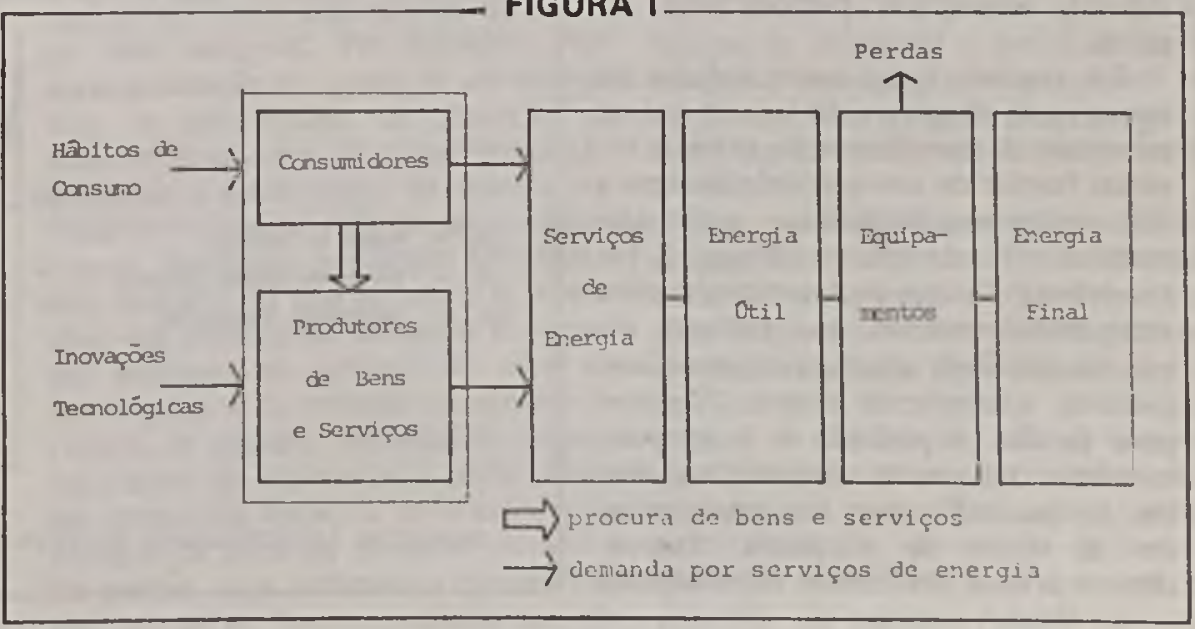


ticas, as de transporte e distribuição, bem como aquelas voltadas para o lazer ou as que dão origem a maiores niveis de conforto, geram, tal como ilustra o gráfico, uma demanda por bens e servicos que, por sua vez, traz embutido um conjunto de necessidades de serviços energéticos - aquecimento, iluminação, etc. - que são expressas por determinadas quantidades de energia útil (lúmem/ $\mathrm{m} 2, \mathrm{Kcal} / \mathrm{h}$, etc.). Estas últimas são obtidas através do estoque existente de aparelhos e equipamentos conversores de energia, a partir da energia final posta à disposição do consumidor direto ou do produtor de bens e serviços pelas concessionárias.

O gráfico também permite, ao longo deste fluxo de bens, serviços e energia, definir e identificar as oportunidades de conservação. Em primeiro lugar, estas aparecem onde se obtém uma composição diferente no fluxo de bens e serviços ou na forma com que são produzidos, seja através de modificações nos padrões de gosto e de hábitos de consumo, da presença de novos produtos, da introducão de critérios de projeto e, sobretudo, de inovaçōes tecnológicas nos processos de produçāo. Estas mudanças alteram a composiçăo do conjunto de serviços energéticos, com repercussões nos requisitos de energia útil, podendo torná-los menores.

São exemplos destas possibilidades a regulagem de termostatos dos condicionadores de ar para niveis de temperatura mais baixos, alteraçōes na concepçāo de projetos arquitetônicos garantindo melhor condicionamento ambiental das edificações, níveis mais baixos no iluminamento artificial (compatível com a fisiologia humana), novos recursos de projeto de iluminação, tais como: iluminação diferenciada por tarefa e sistemas de controle, e, ainda a introdução de algumas tecnologias eletrotérmicas de ponta.

Em segundo lugar, oportunidades de conservação decorrem do fato de que os processos de transformação entre as diversas formas de energia - de final para útil, nos termos do gráfico - estão submetidos a leis de natureza física $\left({ }^{1}\right)$. Estas definem limites de desempenho para estas transformações, que excluem niveis de eficiếncia absoluta e conseqüentemente, estabelecem níveis mínimos para perdas. A redução e o aproveitamento das perdas decorrentes destes processos $\left({ }^{2}\right)$, com isso aproximando os níveis de eficiência observados na prática dos limites teoricamente definidos através de métodos, técnicas ou práticas variadas, correspondem à acepção mals usual do termo conservação.

Disso são exemplos: as modificaçōes no desenho e carcaça de motores, a utilização de reguladores de freqüência e tensão, as instalações de recuperadores e economizadores de calor, o isolamento de linhas de distribuiçäo de vapor, a introdução de equipamentos, lâmpadas, luminárias, motores e ignitores mais eficientes e mais versáteis, etc.

Naturalmente, situações concretas envolvendo oportunidades de conservação contêm elementos que permitem classificá-las ora numa, ora noutra, ou em ambas as alternativas descritas, dificilmente correspondendo a uma esque matização estrita.

Defjnidas as oportunidades materiais de conservação( $\left.{ }^{3}\right)$, cabe agora especificar as forças que, por um lado, condicionam o aparecimento de novos hábitos de consumo, o surgimento de novos produtos e avanços tecnológicos contendo uma demanda por serviços energéticos menos exigente em termos de energia útil, e que, por outro, determinam a adoçāo de práticas e métodos que resultem em niveis de eficiência maiores nas transformações energéticas.

A discussão que se segue focalizará o efeito sobre estas variáveis de modificações no sistema de preços, que supostamente indicam a escassez relativa de bens, serviços e fatores de produção, entre estes incluido o fator energia. Exa. mina-se, de início, o efeito de alterações na estrutura de preços numa perspectiva de curto a médio prazo, em que estão excluidas ou são despreziveis as possibilidades de avanço tecnológico. Em seguida, examina-se a relação entre a mudan. ça de preços e a inovação tecnológica.
2.2 A conservação através da substituição de energia por outros insumos à produção ou através da mudança na estrutura de consumo

A utilização de energia final, quer como insumo à execução de uma atividade econômica, quer como elemento de apoio à realização de atividades de lazer, conforto ou produção domésticas, faz-se sempre acompanhada da utilização de outros insumos, na forma de equipamentos, matérias primas ou mãode-obra, em combinações de quantidades de energia e destes outros insumos que são determinadas pelas tecnologias de produção disponiveis e pela relação vigente entre os preços de energia e dos demais insumos.

A esta formulação corresponde o conceito de função de produção, o qual é ilustrado no gráfico por meio de isoquantas ou curvas que mostram as várias combinações do insumo energia e do insumo não-energia (admitindo-se, para fins de simplificação, este úl timo como sendo um insumo agregado, correspondente aos demais insumos não-energéticos), utilizados na produção de uma mesma quantidade de um bem ou serviço qualquer.

A unidade produtiva lou a sociedade) deve promover a minimização dos custos de produção. Esta ocorre no ponto a, de tangências da curva de isocustos C1, que especifica um determinado n'vel de dispêndio ou custo total de produção, com a isoquanta $\mathrm{Q} 1$, que especifica o nivel de produção $X$. Ao minimizar os custos, encontra-se os pontos $E^{*}$ e Nê, que indicam a combinação mais eficiente das quantidades de energia e não-energia a serem utilizadas na produção de $\mathrm{X}$ unidades do bem considerado,

\section{FIGURA 2}

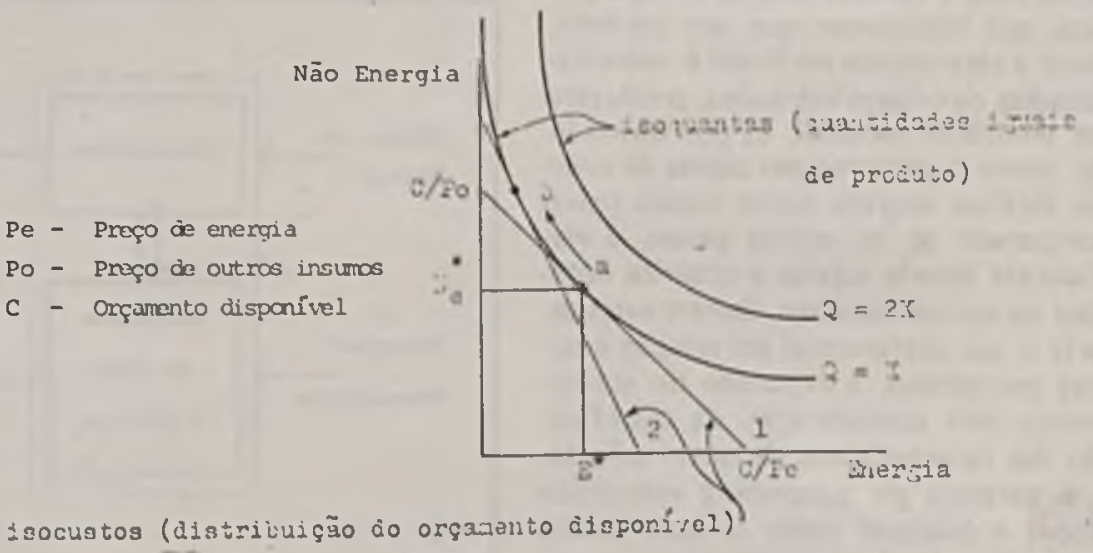

Lsocustos (distrilujçघ̆o ỏo orçamanto cisfonírel) 
quando vigoram os preços Pe e Po para energia e outros insumos.

Modificações na relação de preços energia/outros insumos, tais como: as que decorreram do aumento dos preços de petróleo na década de 70 , quebram a estabilidade destas combinações, desde que a natureza da tecnologia permita, induzindo os consumidores de energia a substituíla por capital e mão-de-obra, para produzir a mesma quantidade de bens ou serviços que anteriormente.

Admitindo-se um aumento nos precos de energia relativo ao de outros insumos, temos, nos termos do gráfico, que a curva de isocustos aumentaria sua inclinação de C1 para C2, indicando, para um mesmo nivel de gastos $C$, a menor participação física da energia. Conseqüentemente, desloca-se o ponto de tangência de a para $\mathbf{b}$, indicando uma nova combinação entre insumos energéticos e não-energéticos( $\left.{ }^{4}\right)$.

Do ponto de vista termodinâmico, o deslocamento ao longo da isoquanta no sentido do menor consumo de energia ( de a para b) indica a diminuição de per. das, e, portanto, um maior nivel de eficiência na transformação energética: para um mesmo nível de energia útil, menores quantidades de energia final. Um exemplo disto é o maior zelo em serviços de manutenção e o isolamento da distribuição de vapor.

Nessas condições, o resultado do aumento do preço de um energético - tal como a experiencia sugere no caso do petróleo - foi a diminuição de seu consumo e a redução na relação $E / P$ ( $E$, energia e $P$, produtol, observando-se, sem muito esforço, que a modificação na relação de preços, ao se apresentar desfavorável ao uso de insumos energéticos, por si só exerce uma exigência pela conservação destes recursos $\left({ }^{5}\right)$.

No Brasil, nos últimos dez anos, a questão da conservação de energia elétrica teve pouco fôlego e por boas razões, uma vez que tem-se considerado que seus preços estiveram, neste perío do, abaixo do que seriam seus custosoportunidade, o que, pela mesma lógica de minimização de custos aplicados acima aos consumidores de petróleo, deve ter, no caso da energia elétrica, acentuados padrōes intensivos de consumo de energia, em detrimento da utilizaçäo de outros insumos, continuando o consumo de energia elétrica a crescer a taxas altas.

A adoção de tarifas realistas, que expressam com justeza os custos-oportunidade da oferta do serviço de energia elé- trica, inclusive nas suas variaçōes diárias e sazonal, estimulará e determinará os limites, quase se diria "naturais", para a conservação de energia elétrica. A conservação ou poupança arbitrária de energia elétrica, acima dos niveis ditados por preços que reflitam adequadamente custos-oportunidade, significa o gasto, também arbitrário e a mais, de outros insumos.

Pode ocorrer, no entanto, que a na. tureza da função de produção, vale dizer, das técnicas disponiveis, não admita substituiçäo significativa entre insumos. Nesse caso, as modificações nos preços dos energéticos afetam diferentemente os preços dos diversos bens ou serviços que os utilizam.

Dentro da estratégia do consumidor de manipular sua renda de forma a maximizar os beneficios pessoais dela derivados, e como conseqüência do aumento dos preços de energéticos, aqueles produtos em cujos preços houver uma repercussão acentuada, poderão sofrer alteraçōes nos seus padrōes de demanda, sempre que para eles houver substitutos proximos que requeiram um consumo energético menor.

Esta alternativa não implica, em si, quer a obtenção de maiores eficiências de transformaçāo, quer a redução de necessidades de energia útil, a nível de ca. da bem ou serviço. A redução do consumo de energia decorre da modificação na composição da demanda global por energia útil. É o caso por exemplo, da substituição do transporte individual pelo transporte público de massa.

\subsection{O avanço tecnológico e o cresci- mento econômico como condi- cionantes da conservação}

A questão da conservação tem implicaçöes diferentes dependendo do ponto de vista temporal. Por exemplo, logo após a elevação do preço de um energético, as perspectivas de obtenção de maiores resultados de conservação são limitadas à substituição de energia por matérias primas ou mão-de-obra. Alguns outros resultados poderiam ser esperados também no que se refere às altera. çōes nos padrões de demanda. É o caso, por exemplo, da reduçāo do nível de termostatos e da redução do número de viagens de passeio. No entanto, poucos resultados são esperados, a curto prazo, em termos da melhoria da eficiência do estoque de bens de consumo durável e de capital, cuja estrutura e caracteristicas, em geral, foram estabelecidas por uma relação de preços de energia/outros insumos anterior à vigente após o aumento dos preços de energia.

A longo prazo, a questão torna-se substancialmente diferente, estando a viabilidade da conservação intimamente vinculada tanto à ocorrência de mudanca tecnológica quanto às taxas de crescimento da economia.

Modificações tecnológicas ocorrem na fabricação de bens ou serviços conhecidos (exemplos: nos sistemas de trans porte de massa, nos processos construtivos, etc.), na melhoria qualitativa dos produtos tradicionais (ex.: lâmpadas de sódio) e no aparecimento de novos pro dutos (ex.: recentes, sensores de presença, sistemas de controle micro-eletrônicos).

O significado micro-econômico da mudança tecnológica é o de permitir a produção de uma mesma quantidade de bens ou serviços com menores quantidades dos diversos insumos envolvidos, energia e outros. Equivalentemente, a inovação procede como se tivesse aumentado a quantidade dos insumos à produção, podendo apresentar tendência favorável ao aumento por igual de todos os insumos, quando é chamada de neutra, ou favorável ao aumento mais acentuado de apenas um ou alguns dos insumos $\left({ }^{6}\right)$. No caso de viés favorável à energia, a modificação tecnológica leva a uma solicitação diferente de serviços energéticos e a requisitos menores de energia útil.

O processo de geração das modificaçōes tecnológicas é extremamente com. plexo e de mecanismos insuficientemente conhecidos, tendo sido primeiramente tratado como exógeno ao funcionamento do sistema económico. Há, no entanto, uma tendência a tratálo endogenamente, compreendendo-se que "uma mudança nos preços relativos dos fatores de produção é por si só um incentivo à invenção, e à invenção de um tipo específico dirigido à poupança do fator que se tornou relativamente caro". (Hicks, 1963).

Ora, nessa visão o encarecimento dos preços de energéticos seria uma précondição para empurrar à frente o pró prio desenvolvimento tecnológico que levaria à poupança desse insumo. Assim, por exemplo, a concessão de subsidios poderá ser ineficiente, não só no sentido de indicar uma substituição inadequada entre energéticos, como também por dificultar a introdução de tecnologias mais inovadoras. Este é o caso, por exemplo, da política recente com rela- 
cão à eletrotermia. Esta favoreceu a utilização de energia elétrica para produção de vapor em caldeiras que, mesmo que se apresentassem na versão mais eficiente existente no mercado, precludiriam modificações tecnológicas mais interessantes e que se poderia ter incentivado através de preços mais aitos. Seria, por exemplo, o caso de uma modificação substancial nos próprios processos de producão que requerem a utilização de vapor. (Serra e Pagy, 1984).

A viabilidade da conservação está vinculada não só à ocorrência de mudança tecnológica, embora possa ocorrer de forma relativamente independente da criação de capital (ex.: desenvolvimento e aplicação de técnicas de pesquisa ope. racional à organização da produção), requer, em regra, sua incorporação a novo capital. A introdução da eletro-siderurgia, por exemplo, requereria pesados investimentos em instalações e equipamentos. Portanto, é dificil imaginar uma taxa acentuada de conservação de energia que venha a ocorrer, não só na ausência de mudança tecnológica, como na ausência de novos investimentos que permitam a introdução, nelas incorporadas, dessas inovações tecnológicas.

Assim, a longo prazo pode ocorrer a reposição do estoque de bens de consumo durável por aparelhos mais eficientes, dentro dos prazos requeridos para pesquisa, desenvolvimento, desenho e reequipamento das linhas de produção, e na medida das taxas de reposiçāo permitidas pelo crescimento da renda pessoal. Pode ocorrer, também, a renovação do estoque de capital, um processo bem mais complexo e que poderá atingir desde os equipamentos, as instalações fabris, a forma de construir as edificações, até as estruturas de transporte e mesmo os padrões de uso do solo. Esta renovação irá depender das taxas de crescimento econômico, da taxa de formação bruta de capital fixo, ou seja, dos investimentos fabris, da expansāo da indústria de construção civil e dos investimentos em infra-estrutura urbana, sobretudo, nos transportes.

\section{A perspectiva do consumidor, da concessionária $\theta$ da sociedade}

A reação, esperada por parte de consumidores e concessionárias, à existência de oportunidades de conservação, bem como a definição de qual seja o interesse da sociedade no aproveitamento des. sas oportunidades, vai depender das suposições que se faça quanto às motivações de comportamento de consumido- res e concessionárias. Da mesma maneira, expectativas quanto ao processo de surgimento de inovações e ao comportamento de empresas interessadas em produzi-las dependem dos modelos de análise utilizados.

Por exemplo, garantidas certas condições ideais de funcionamento dos mercados de energia e dos demais bens, poder-se-ia supor que os interesses dos consumidores, das concessionárias e da sociedade estariam sendo atendidos. Nestas condições, por exemplo, os consumidores aproveitariam instantaneamente 0 conjunto de oportunidades de conservação que viessem a ser trazidas ao mercado, dando ensejo a uma diminuição progressiva nas taxas de crescimento da demanda por energia, fato que seria adequadamente considerado pelos produtores na elaboração de seus planos de oferta.

Neste item, apresentam-se alternativas, mais próximas da realidade do que a mencionada acima, através do exame, primeiramente, da situação em que o consumidor não reage oportunamente às oportunidades de conservação e, a seguir, daquela em que a concessionária, ưm monopólio regulado, se vê diante de alternativas diferentes para atendimento aos seus consumidores, uma, via expansão de oferta, outra, via a adoção de práticas de conservação. Neste último caso, a concessionária se vê obrigada a estabelecer regras que permitam definir a quantidade de recursos a serem alocados ao programa de conservação. Finalmente, descreve-se um modelo normativo de oferta de energia, através do qual se estabelecem estratégias de custos minimos para expansäo do sistema, onde se garante o atendimento das exigências do consumidor, da concessionária e da sociedade.

\subsection{O consumidor de energia}

Ao tomarem suas decisões de compra e investimento, os consumidores de energia detêm, teoricamente, todas as informações necessárias para fazê-lo de forma racional, atendendo assim, quer as exigências produtivas de minimização de custo (quando se requer que seja igual o produto marginal decorrente da aplicação das últimas unidades monetárias que forem gastas tanto em energia como em outros insumos), quer às condiçōes de maximização de seu bem-estar (quando se requer que the seja equivalente à satisfação que deriva da última unidade monetária gasta com a compra, tanto de energia, quanto de outros bens e serviços) $\left({ }^{7}\right)$.
Espera-se que o consumidor se com. porte de forma igualmente racional diante das perspectivas de conservação de energia que lhe estão abertas - o que equivale a identificar os custos dos insumos não-energéticos (materiais e equipamentos) necessários à implantação das medidas de conservação e a avaliar os benefícios da conservação em termos dos custos dos insumos energéticos que se economizam, escolhendo-se o nível de conservação que maximiza a diferença entre beneficios e custos $\left({ }^{8}\right)$.

"As alternativas relativas a investimentos em conservação podem se apresentar ao consumidor sob a forma de diferentes problemas" (Marshalle Ruegg, 1980), tais como o de aceitar ou reje itar um certo projeto de conservação, o de escolher prioridades dentre um conjunto de alternativas, o de se obter o mais rápido retorno dos recursos investidos, ou, ainda, o de se determinar o nivel economicamente ótimo do investimento em conservação.

Em termos operacionais e analiticos, dependendo da forma em que o problema se apresenta, assume-se que o con. sumidor estaria fazendo uso de um dos métodos usuais de análise de investimento, ou seja, valor atual, taxa interna de retorno, custo/beneff́cio e tempo de retorno. A dificuldade maior na aplicaçāo desses métodos está na determinaçāo das taxas de desconto (exceto, é claro, no caso do método de taxa interna de retornol, como decorrência da introdu. ção do fator tempo.

Assim, suponhamos a avaliação da viabilidade de um determinado equipamento em tudo comparável a uma alternativa energeticamente menos eficiente, exceto no tocante a seu preço inicial mais caro. Adotando-se o método do valor atual para comparar os dois equipamentos e utilizando-se taxas de descontos representativas de oportunidades de investimento que estejam abertas ao consumidor, ou então de juros e demais custos das linhas de crédito existentes para a compra de equipamentos, observa-se, por hipótese, que, apesar do custo inicial maior, o equipamento mais eficiente tem um menor valor atual dos custos líquidos ao longo da totalidade do seu periodo de vida. Este resultado indicaria ao consumidor racional que deveria comprar o equipamento mais eficiente.

Uma vez determinado o interesse em se fazer um investimento em conservacão, supōe-se, teoricamente, que o consumidor aja instantaneamente e efetue o 
investimento. Ora, seria de se esperar, segundo esta expectativa, que fosse muito acelerada a taxa de penetração no mercado de produtos, técnicas e práticas de conservação eficiente do ponto de vista econômico. No entanto, não é necessário uma observaçāo muito acurada para se verificar que estes ajustes não são instantâneos, não só nos mercados de conservação como em quaisquer outros mercados de novos produtos.

Existe, como se sabe, um processo de introduçäo gradativa de novos produtos - geralmente descrito por uma curva om $S$-, o qual corresponde à eliminação de barreiras à adoção do produto. Isso significa que, para uma mesma data de referência, os consumidores aplicam, na avaliaçāo de seu interesse pelo novo produto, diferentes taxas de desconto, dependendo das características de seu perfil pessoal (nível de renda, aversão a risco, etc.). Os que adotarem a inovação mais cedo apresentam, implicitamente, taxas de desconto menores do que os que as adotarem mais tarde.

$\mathrm{Na}$ literatura sobre o assunto há um sentimento bastante generalizado (Hausman e Josk ow, s.d.), baseado em razoá. vel evidência empírica de que as taxas implicitas de desconto aplicadas pelos consumidores no exterior são de fato muito altas. A partir de um crescente número de estudos, pode-se dizer que as taxas de desconto estão muito acima tanto daquelas normalmente utilizadas nas análises de engenharia económica para escolha de bens de consumo durável, quanto das taxas segundo as quais os consumidores tomam recursos emprestados ou aplicam seus fundos. Isto é tomado como prova da existência de falhas de mercado muito nitidas, tais como, custos altos de obtenção de informações e falta de acesso a financiamentos para fazer face a investimentos iniciais, em particular para os grupos de baixa renda.

A constatação, portanto, a partir da experiencia estrangeira é a de que o consumidor, como conseqüência sobretudo de falhas de mercado, não reage prontamente as oportunidades de conservação que lhe estão abertas, assumindo-se que estas existam concretamente. No caso brasileiro, não sర ainda não es. tão presentes no mercado um número significativo de equipamentos e aparelhos mais eficientes, como também, os preços baixos da energia elétrica dificultam, tanto o aproveitamento daquelas oportunidades existentes, quanto o surgimento de novas.

FIGURA 3

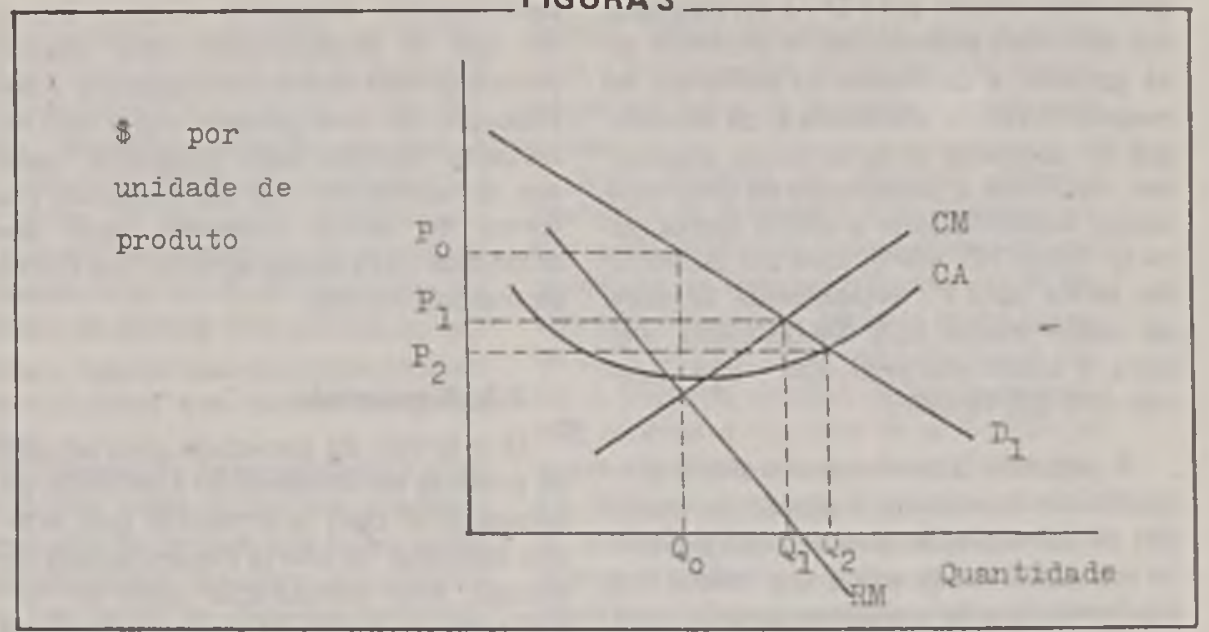

\subsection{A concessionária}

A suposta reação da concessionária, como se disse, vai depender do modelo adotado para análise de seu comportamento. Considerando-a como um monopólio regulado, temos, observando o Gráfico, que para uma configuraçāo da demanda, D1, e para curvas de custos marginais, $\mathrm{CM}$, custos médios, $\mathrm{CA}$, e receitas marginais, $R M$, o monopólio nāo regulado fixaria em $P_{0}$ e $Q_{0}$ londe o custo marginal é igual à receita marginal) o preço da energia e a quantidade que estaria disposto a produzir. $O E_{s}$ tado, no entanto, através dos órgãos normativos e reguladores, fixa o preço em $P_{1}$, onde o custo marginal é igual à demanda, e faz aumentar a quantidade ofertada pela empresa para $Q_{1}$.

Com isso, tanto o consumidor paga menos por maiores quantidades de energia, quanto retira-se do produtor parte do seu poder de monopb́lio, fazendo-se com que se chegue a niveis de produto e preço que correspondam mais de perto aos que deveriam ocorrer caso vigisse uma situação onde os mercados fossem perfeitamente competitivos. $\mathrm{Na}$ realidade, os órgãos reguladores costumam estabelecer o preço de energia ao nível no qual ele se equaliza ao custo médio $\left(\mathrm{P}_{2}\right)$. al incluído uma remuneração de investimento arbitrada $(10$ a $12 \%$ ao ano, teoricamente, no caso brasileiro) 8 , a este preço, correspondendo a quantidade $\mathrm{Q}_{2}$.

Suponhamos que, num dado momento, a demanda de determinada área seja expressa pela curva $D$, associada ao nível médio de eficiência e, da tecnologia de consumo disponivel, e que a concessionária dimensione sua oferta para $Q$ (40 $\times 10^{9} \mathrm{kWh}$ ) a uma tarifa $\mathrm{P}$, igual ao custo médio de suprimento (US $\$ 0,05$ / kWh $\left./ l^{9}\right)$. Se, num momento seguinte, a

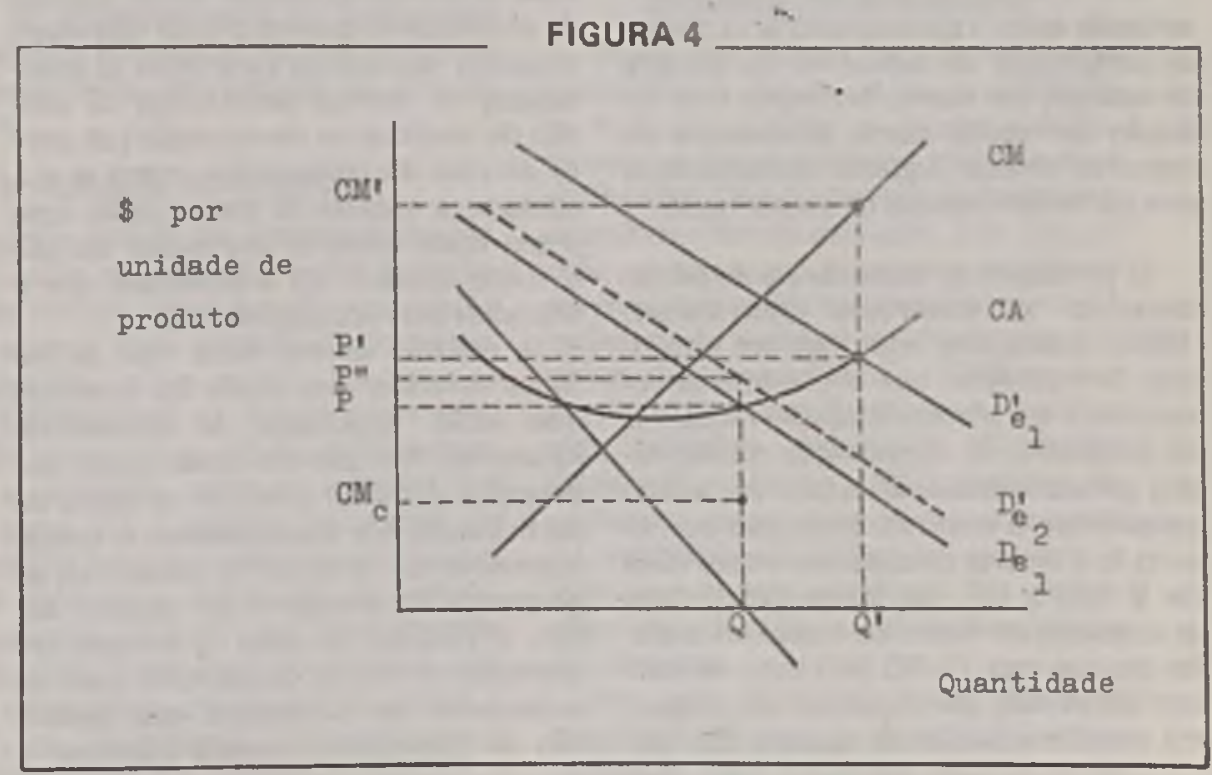


demanda crescer para $D^{\prime}$, a concessionária terá duas alternativas. A primeira será garantir a satisfação da demanda, ao mesmo nível de eficiência e, da tecnologia de consumo anteriormente disponivel, mediante a construção de uma nova usina, expandindo-se a oferta global para $Q^{\prime}\left(50 \times 10^{9} \mathrm{kWh}\right)$, com um aumento da tarifa para $\mathrm{P}^{\prime}$, estabelecida também ao custo médio (US $\$ 0,06 / \mathrm{kWh}$ ), embora o custo marginal, CM', seja superior (US $\$ 0,10 \mathrm{kWh}$ ).

A segunda alternativa envolve a con. cessão de incentivos à adoção de medidas de conservação, provocando portanto um aumento da eficiência média dos equipamentos de consumo para $\mathrm{C}_{2}$, que permite $o$ atendimento à mesma demanda $D^{\prime}$ sem ampliação da oferta global, cujo nivel se mantém em Q $140 \times 10^{\circ}$ $k W h)$. Supondo-se que o incentivo seja fixado em US $\$ 0,03 / \mathrm{kWh}$ poupado, que corresponde, portanto, ao custo marginal de se evitar a expansão, $\mathrm{CM}_{\mathrm{C}}$, ou, por outra, ao custo marginal do aumento de eficiéncia média da tecnologia de consumo. Isto corresponde a um deslocamento da curva de demanda que descreve os novos requisitos de energia final de $D_{C_{1}}^{\prime}$, para $D^{\prime} c_{2}$. A concessioná. ria assim atende ao crescimento da de manda sem ampliar a oferta, estabele. cendo uma tarifa P" (igual ao custo mé. dio de US $\$ 0,575)$, menor que o que vigoraria, caso fosse adotada a primeira alternativa, dessa maneira beneficiando a todos os consumidores, embora a uns (os que adotaram as práticas de conser. vação) mais do que a outros.

Como se vê, se, por um lado, a conservação evita à concessionária os custos de construção de usinas ou de compra de energia, por outro, Ihe impöe uma redução de receita como decorrência de menores vendas àqueles consumiutores que adotaram práticas de conservação.

O princípio da inexistência de perde dores, o "no losers'rule" (Wirtshafter, 1985), estabelece, com base em exigên cias de eqüidade, que o máximo de incentivo a ser oferecido aos participantes de programas de conservação patrocina. dos pelas concessionárias deve ser a diferença entre o custo de produção que se evita e a receita perdida (no nosso caso de $\$ 400 \times 10^{6}$. ou $\$ 0,04 / \mathrm{kWh}$ ). Caso se estabeleçam niveis de incentivo maiores do que este $(>\$ 0,04 / \mathrm{kWh})$, os con. sumidores não participantes do programa estarão subsidiando aqueles que são participantes, enquanto niveis menores do que os estabelecidos pelo mesmo principio tem como conseqüência a distribuição de uma parcela maior dos resultados obtidos pelo programa, quer aos consumidores não participantes (na forma de tarifas menores), quer aos acionistas das concessionárias (na forma de maiores lucros).

\subsection{A sociedade}

O interesse da sociedade pela adoção de práticas de conservação é definido ao compará-las com alternativas que estejam baseadas na oferta inquestionada de energia. Esta comparação pode ser for. malizada de maneiras diversas, uma das quais (Sanghvi, 1984) através da inclusão do potencial de conservação em modelos globais de oferta que ordenem e dêem prioridades àquelas alternativas que implicarem em custos mínimos na expansão do sistema elétrico. Neste caso deverão ser minimizados os valores presentes dos custos de capital e operação correspondentes aos investimentos feitos tanto pelo lado da concessionária, quanto pelo lado do consumidor.

Uma estratégia de minimização de custos de oferta de energia envolve a realização de um inventário dos recursos energéticos passiveis de utilização - inclusive dos recursos oriundos da adoção de práticas de conservação - e a especificação de curvas de oferta para cada um destes recursos, ou seja das curvas que indiquem os custos marginais de produção ou conservação das unidades adicionais de eletricidade. A especificação da curva de oferta de conservação envolve levar-se em consideração tanto o preço da eletricidade quanto o valor dos investimentos necessários para obter as quantidades de energia decorrentes da adoção de medidas de conservação (do ponto de vista do consumidor, como se viu, adota-se a medida de conservação, caso - seu custo unitário seja menor do que - custo unitário da eletricidade que é oferecida pela concessionária).

A questão central neste tipo de en. foque refere-se aos niveis de incerteza que estão associados às alternativas existentes. No caso da conservação, por exemplo, difícil predizer os níveis de participação dos consumidores e, conseqüentemente, projetar o potencial de poupança de energia a ser obtido. Assim, a decisão de adiar a entrada em operação de novas usinas com base na expectativa de poupanças que podem não se concretizar poderá significar a promoção, em caráter de urgência, de obras visando ampliar a oferta de capacidade, o que implica, nestas condiçōes, em custos mais altos. Por outro lado, a construção de excesso de capacidade im. plica na imposição de tarifas mais altas e na absorção de capitais que seriam meIhor empregados em outros setores da atividade econômica e social.

\section{Instrumentos para uma politica de conservação}

A constatação de que existem oportunidades de conservação e que estas devem ser contempladas pela política energética, leva, dada à modesta experiência brasileira na questão, ao exame dos instrumentos mediante os quais isto seria feito, sobretudo, com base em exemplos estrangeiros.

Esses instrumentos podem ser classificados com base na sua dependência do mecanismos de preços (política de preços, aplicação de impostos) ou, alternativamente, com base na sua tentativa de substituição dos mecanismos de mercado, através da definição, centralizada, de critérios de alocação de recursos (fixação de quotas, fixação de padrões de desempenho). Podem, também, agru. par-se na categoria dos instrumentos que se voltam para a correção de falhas no funcionamento dos mercados de energia (fornecimento de informaçōes, tentativa de persuação e convencimento, concessão de empréstimos, incentivo à pesquisa e ao desenvolvimento tecnológico).

A escolha do instrumento mais adequado dependerá, primeiramente, dos resultados da avaliação que se fizer quanto à natureza do problema (ex.: está-se, efetivamente, diante de uma falha de mercado?). Em segundo lugar, os ins. trumentos deverão se adequar a objetivos de eficiência e eqüidade claramente especificados. Em terceiro, sua definição irá depender da preferência do administrador por soluções de decisão centralizada ou daquelas que se baseiam no exercício da livre escolha pelo consumidor.

A proposição da utilização de instrumentos, no caso nacional, não se tem feito acompanhar pela proposta de critérios e métodos de avaliação da sua eficácia. Certamente, que a avalíação dos resultados deste tipo de iniciativa é mujto dificil, dada à multiplicidade de influências que ocorrem, ao mesmo tempo, sobre o consumo de energia (varia. ções conjunturais no nivel de renda e 
produçāo, mudanças climáticas, modificaçōes na estrutura de produção, etc.), o que torna problemático o isolamento de uma medida especifica para análise. No entanto, há o desenvolvimento de metodologias adequados para este fim (Berry e Hirst, 1983), o que permitiria monitorar o alcance das diversas medidas utilizadas.

\subsection{Política de preços}

Caso o sistema de preços seja aceito como um mecanismo eficiente de alocação de recursos, a prioridade inicial de uma polftica de conservação de energia é equalizar os preços dos energéticos ao nivel de seus respectivos custos marginais, inclusive nas suas variaçōes diárias e sazonal, introduzindo-se, em seguida, as modificações necessárias para que se leve em conta os objetivos cabiveis de eqüidade social (Munasinghe, 1983).

O fator determinante na adoção de práticas de conservação de energia por parte dos consumidores é, indubitavelmente, a relaçāo entre os preços de energia e os custos das práticas de conservação que vierem a adotar. Assumindo-se que as tarifas de energia elétrica nāo traduzem seus custos de oportunidade, situando-se há uma década com valores decrescentes e abaixo dos níveis adequados de remuneração do setor, as técnicas de conservação aparecem, assim, como desinteressantes, já que preços baixos de energia tornam inviáveis a recuperaçäo dos investimentos feitos pelos consumidores. Dessa maneira, verifica-se um consumo maior de energia elétrica do que ocorreria na vigência de niveis tarifários mais altos. Na realidade, a correta definição dos níveis tarifários é uma précondição para uma política de conserva. cão. Não há como supor viável a utilização de qualquer outro instrumento sem 0 apoio de preços adequados.

O controle de preços, não só estabelece uma sinalizaçāo inadequada entre fatores, como também entre os diversos insumos energéticos, indicando, por exemplo, como viável uma substituição eventualmente desinteressante de derivados de petróleo por energia elétrica, ao mesmo tempo que impedindo o aparecimento de outras fontes energéticas, sobretudo renováveis, que poderiam trazer uma contribuição, por modesta que fosse, à oferta global. Finalmente, por um lado, ao estimular o consumo e, por ou tro, ao reduzir receitas e margens de lucros, o controle de preços leva ao desequilíbrio econômico-financeiro do setor, desestimulando a produção.
Outra questão importante na definicão da política de preços é a da presença de externalidades a nivel da produção, ou seja, daquelas situaçōes em que o custo marginal social de produção $\left({ }^{10}\right)$ esteja acima do seu custo marginal privado e onde se configure, do ponto de vista social, uma produção excessiva e a existência de preços mais baixos do que os ótimos, mesmo que os preços tenham sido equalizados aos custos marginais privados.

A existência de externalidade a nivel de produção pode se dar por exemplo, na produção de origem hidráulica londe as externalidades estariam situadas no ámbito da perda de recursos naturais). na de origem térmica (onde estas estariam situadas no âmbito da poluição), ou na geração nuclear (onde estas poderiam estar situadas em várias áreas). Nestes casos, a politica de preços deve fazer com que os preços correntes reflitam os custos marginais sociais, situaçāo em que a procura diminuirá, encarregandose de promover a eliminação do excesso do consumo e definindo menores taxas de expansāo do suprimento.

Finalmente, no tocante à política de precos, deve-se dizer que é importante avaliar as repercussöes do encarecimento dos preços relativos de energia nos diversos grupos de renda. A experiência estrangeira (Griffin e Steele, 1980) indica que o encarecimento dos preços de energéticos incide mais fortemente nos grupos de renda mais baixa, em cujos orcamentos o componente custo da energia é percentualmente mais alto do que naqueles dos grupos de renda mais alta. Neste caso, se estiverem presentes obje. tivos de eqüidade social na formulação da política energética, há que se procurar mecanismos de correção da alta de preços.

\subsection{Aplicação de impostos}

Agindo através do sistema de preços, a aplicaçāo de impostos sobre o consumo de energia elétrica pode servir como instrumento para redução do consumo, a depender, como se viu, do valor da elasticidade-preço da demanda por energia de curto prazo. Como instrumento, tem a vantagem, sobre os métodos que não agem via o sistema de preços, de apresentar baixos custos de administracão e controle e, sobretudo, de preterir, exatamente, aqueles usos considerados como mais "desvalorizados" pelo próprimidor, minimizando, assim, a perda de "bem-estar" social decorrente da imposiçāo do imposto /Griffin e
Steele, 1980). No entanto, esse método tem a desvantagem de apresentar efeitos negativos sobre os grupos de renda mais baixa.

Uma variação do imposto sobre o consumo de energia é a do imposto sobre o equipamento pouco eficiente, que apresenta as mesmas características gerais que o primeiro, embora tenha alcan. ce mais restrito, pois, embora possa afetar o nivel do estoque do equipamento, não alcança a sua taxa de utilização ou a sua eficiência efetiva. Essa alternativa, no entanto, provocará menos oposiçāo e poderá garantir recursos, eventualmente transferiveis como subsídios aos usuários de equipamentos mais eficientes.

\subsection{Fixação de quotas}

Existem alternativas para a promocão da redução do consumo de energia que não se baseiam nos mecanismos de mercado, é o caso da imposiçāo de quotas (ex.: o racionamento de energia elétrica por zonas, o fechamento de postos de gasolina aos sábados e domingos, etc.). Supõe-se que, em certas condiçōes, quando a curto prazo a elasticidade-preco dos energéticos tende a ser menor do que a longo prazo, a fixaçäo de quotas pode atê vir a ser uma iniciativa mais efetiva do que a manipulação do sistema de preços. No entanto, como no caso das demais soluçōes que não passam pelo mercado, tem vantagens nitidas e óbvias do ponto de vista de seus efeitos sobre os grupos de renda mais baixa.

\subsection{Definicão de normas e fixação de padrōes de desempenho}

Outro mecanismo fora de esfera do mercado é o que se apóia na definiçāo de normas e padrões de fabrico e de desempenho e que pode ser aplicado para edificaçōes, equipamentos industriais e aparelhos eletrodomésticos. Esse tipo de açāo caracteriza o programa alemão de normas para caldeiras industriais, o canadense, de padrões de eficiências mínimas de fornos (OECD, 1976) e, ainda, o programa californiano de padrōes para aparelhos domésticos (California Energy Commission, 1983). A defesa da utilização desse mecanismo se assenta na existência de falhas de mercado, e cumulativamente, no caso de edificações, na ocorrência de externalidades de consumo.

No caso específico do mercado de aparelhos elétricos, a introduçāo de modalidades mais eficientes esbarra na in- 
suficiência de informação disponível para o consumidor. A fixação de padrões de desempenho é freqüentemente lembrada como solução para esta falha de mercado. No entanto, melhor parece ser a mera indicaçāo ao consumidor das características de desempenho dos diversos equipamentos (como nos programas de utilização de etiquetas de desempenhol, deixando-se que ele tome sua própria decisảo quanto ao nivel de eficiência, dentre outras características, que lhe convém consumir. É até mesmo possível que a imposição de padrões minimos de desempenho levaria a um efeito perverso, através de modificações do comportamento do consumidor, redun. dando no aumento do consumo (Hausman e Joskow, s.d.).

No caso das edificaçōes, o mesmo raciocínio que levaria apenas à mera provisão de informações ao consumidor quanto às caracteristicas de desempenho das construções edificadas ou projetadas, em lugar da exigência de níveis mínimos de desempenho através de posturas municipais, não poderia ser aplicado com a mesma forca. $O$ caso destas se faz mais complexo pela presença de externalidade de consumo, da vida prolongada do estoque de edificações e da interveniêrrcia de muitos agentes nos diversos processos que vão desde a incorporação até a venda ou locação do imóvel. Estas características exigiriam, talvez, um programa de desempenho energético de caráter mandatório. Existe evidência empírica de que a poupança de energia obtida, nestes casos, em caráter mandatório pode ser muito efetiva (Califor. nia Energy Commission, 1983).

\subsection{Fornecimento de informações}

A racionalidade destes programas re. side na suspeita da existência de falhas de mercado (inexisténcia de informações) que perturbam a análise do consumidor. Este, então passa a proceder como se aplicasse altas taxas de desconto na compra do equipamento de conservação, rejeitando-o quando uma análise objetiva da viabilidade de compra deste equipamento o recomendaria.

No fornecimento de informaçōes (e na sua produçåo) deveria estar assentada uma das bases da ação das concessionárias e das entidades interessadas na questão. Aliás, a prática internacional vem indicando este campo como farto em iniciativas as mais variadas (folhetos informativos, manuais de orientação, reuniōes de eslcarecimento, audiovisuais, unidades móveis de demonstração, assessorias a consumidores, etc.). A avaliação dos resultados destes programas é muito difícil. Embora os estudos feitos mostrem resultados contraditórios, há um relativo consenso na necessidade de mantê-los (Berry e Hirst, 1983).

No entanto, talvez já se possa afirmar que a concepção destes programas deverá obedecer a uma série de regras (Sawyer, 1985). Primeiramente, informações generalizadas (do tipo panfleto) atingem apenas os consumidores, cuja tendência pela adoção de uma inovação é marcada. Portanto, os programas que visem a grande maioria de consumidores, cujo processo de aceitação de uma inovação é mais demorado, devem-se fazer mais convincentes. Isso requer que haja mais especificidade nas informações veiculadas, com contatos pessoais e produção de documentos técnicos vol tados para as necessidades de cada tipo de consumi. dor. Segundo, deve-se fazer uso do intercâmbio de informações e experiência dos próprios consumidores, o que tenderá a proporcionar uma veiculação de informacões de caráter mais "terra a ter. ra", além de garantir mais credibilidade à informação e importância ao problema. Terceiro, deve-se estudar prioridades de atuação que levam em conta classes de consumidores, a concentração do consumo de energia, ou ainda o tipo de equipamento/prática/método de conservação, cuja penetração de mercado for mais promissora, ou que garanta maiores resultados.

\subsection{Métodos de persuasáo e conven- cimento}

Estes métodos não têm apoio na racionalidade microeconômica o que não quer dizer que não possam ter sucesso. A tentativa de persuação, na forma de apelos variados à redução de consumo lapague a luz ao sair do cômodo, não tome banhos prolongados, etc.), poderia ser utilizada, quer como alerta para um eventual futuro agravamento dos preços de energia, como introdução a um programa de conservação mais amplo, ou em momentos de crise. É de se esperar efeitos concretos a curto prazo, dependendo da avaliação que o público fizer, da gravidade da situação e, naturalmente, um retorno à posição anterior de consu. mo, tāo logo fosse considerado que a ameaça maior já teria passado, conclu. sỏes estas corroboradas por estudos es. pecificos (Griffin, 1979), realizado nos EUA, quando a administração pública e a imprensa exortavam a população a apagar as luzes, como medida de prote- ção contra o embargo petrolífero de 1973, dada a prevalência da geração tér. mica para eletricidade.

\subsection{Concessão de empréstimos}

A experiência estrangeira indica que, além da mera provisão de informações, vem sendo adotada a prática de aloca. ção de fundos para os consumidores potencialmente interessados na adoção de equipamentos de conservação, na forma de empréstimos a juros de mercado, a juros subsidiados ou mesmo a fundos perdidos, além de prêmios e descontos.

Investimentos em projetos de conser. vação, como em todos aqueles que têm altos custos iniciais, requerem emprés timos, de forma a deslocar no tempo o peso destes custos iniciais. Caso os mecanismos de mercado não garantam a disponibilidade destes empréstimos, seja por inércia, excessiva cautela ou por estarem fechados aos grupos de baixa ren. da, dever-se-ia criar os mecanismos ins. titucionais que os propiciem.

A concessão de empréstimos com subsídios embutidos, de prêmios e de descontos, favorece a viabilidade dos projetos em análise. A razão para concessäo do subsídio requer explicação. 0 consumidor, diante da provisão adequa. da de informaçōes e da disponibilidade do empréstimo a juros de mercado, pode, ainda, manter-se na posição de recu. sa de fazer o investimento em conservação que lhe reduziria os custos. Nessas circunstâncias, caso este investimento seja de interesse da concessionária, por representar a obtenção de energia para oferta a outros consumidores a custo mais baixo do que o da alternativa mais próxima, poder-se-á recorrer à concessão de subsídios que, tornando o investimento mais palatável, acelerará o passo de adoção dos proje tos de conservação e, possivelmente, o número final de con. sumidores que os adotarão.

Esses empréstimos vêm sendo crescentemente utilizados, sobretudo nos EUA (Stern, Berry e Hirst, 1985), sabendo-se que são acolhidos pelos consumidores de forma extremamente varia. da. Para programas de características semelhantes, por exemplo, com empréstimos a juros nulos, observam-se desde quase nenhuma até altas taxas de adesão por parte dos consumidores elegiveis ao financiamento. Acredita-se que, garantidas certas condições, estes possam vir a ter resultados positivos. Possivelmente, incentivos não financeiros - assistência técnica, proteção ao consumidor, a própria administração do programa de con- 
cessão de empréstimo, etc. - desempenham papel-chave na determinação da taxa de adesão do consumidor.

\subsection{Pesquisa e Desenvolvimento Tec- nológico}

As avaliações quanto às possibilida. des resultantes de trabalhos de pesquisa e desenvolvimento no campo da energia tendem a privilegiar o lado da produção de energia e dão pouca atençāo às tecno. logias ligadas ao consumo. Mais recentemente, têm aparecido avaliações das tecnologias voltadas para o consumo com resultados muito promissores e, com base nestas, há quem afirme que, hoje, nos EUA, ao custo médio das novas tecnolo. gias de conservaçāo à disposição do mer cado, não só se torna desinteressante o acréscimo de uma unidade que seja à capacidade do sistema elétrico america. no, como, pelo contrário, deveria ser retirada de operaçāo parte da capacidade existente (Lovins, 1984).
Como se viu anteriormente, o encarecimento dos precos de energia por si só, poderia ser tomado como um incentivo à inovação tecnológica de um tipo que conduzisse à poupança de energia. No entanto, embora nestas condições os preços possam sinalizar a necessidade da inovação e seu favoritismo em relação à poupança de energia, ainda assim, dada a presença das chamadas externalidades, não se tem garantia de que o mercado tenha funcionamento adequado, impe dindo que se defina o nivel ótimo de in vestimento em pesquisas.

A idéia é de que as empresas privadas tendem a subinvestir em pesquisa, porque nem sempre podem se apropriar de todos os benefícios decorrentes do seu trabalho. Isso significa que, na avaliação de projetos de pesquisa, a taxa social de retorno do investimento em pesquisa é mais alta do que a correspondente taxa privada, esta última igual à taxa de desconto do mercado. Assim, é necessário que o Governo aumente os recursos para pesquisa e desenvolvimento até o ponto em que a taxa social de retorno equalize a taxa de desconto do mercado.

Um programa de investimentos em pesquisa requer, então, a definição operacional dos níveis de recursos a serem investidos, das áreas prioritárias no tocante a novos produtos, equipamentos e processos, e dos mecanismos através dos quais se deve agir, sendo exemplares nes. te campo os programas japonês e francês de desenvolvimento tecnológico para racionalização do uso de energia (Energy Conservation Center, 1984 e AFME).

Projeto de pesquisa e desenvolvimento, tanto do lado da oferta de energia, quanto do lado do controle da demanda, levam, igualmente, ao aumento da disponibilidade de unidades de energia, sendo os seus resultados, portanto, comparáveis.

\section{Nota 1}

A primeira lei da termodinámica estabelece que: "A quantidade de energia no universo é constante não podendo ser criada nem destruída, nem mesmo ao ser convertida de uma para qualquer outra de suas várias formas". Formalmente, a primeira lei se expressa como $\mathrm{Q}=\mathrm{W}+$ $\triangle S$, ou seja, a quantidade de energia (Q) que entra num sistema é igual a soma do trabalho produzido pelo sistema (W) com a energia rejeitada pelo sistema (S), sendo esta considerada para efeitos práti. cos, como uma "perda". Eficiência, definida a partir da primeira lei da termodinâmica, é expressa por: $\eta=W / Q$

Não há transformações com eficiência total. Até que ponto estas podem se aproximar de $100 \%$ é uma questẩo abordada pela segunda lei da termodinámica, ao estabelecer uma eficiência teórica máxima. Esta lei diz que: "A proporção da energia que dá entrada num proces. so e que pode ser transformada em trabalho depende da diferença de temperatura de entrada e de salda numa máquina térmica". Em termos de eficiência, a segunda lei ê expressa $X=1-T 2 / T 1$, onde $T 1$ é a temperatura de entrada, T2 é a temperatura de sarda.

Combinando-se a eficiència (W/Q) efetiva (pela 1 ạ lei) de um dado processo, com sua eficiência teórica máxima $(1-T 2 / T 1)$, tem-se uma indicaçăo do potencial máximo de conservação de energia, que pode ser obtido através do uso de uma outra configuração na transforma. ção energética.

\section{Nota 2}

Recorrendo-se aos dados do Balanço Nacional de Energia Útil (BEU) para 1983, tem-se, para a eletricidade, a utilizaçáo de $7.289 \times$ $10^{3}$ tep de energia útil; de $11.294 \times 10^{3}$ tep de energia final, com $4005 \times 10^{3}$, tep de perdas.

A tabela detalha 0 cálculo das energias final e útil, perdas e rendi mentos globais para cada forma de uso fin al do BEU-1983.

\begin{tabular}{lccccc}
\hline & & & \multicolumn{3}{c}{$\times 10^{3}$ Tep } \\
\hline FORMAS DE USO FINAL & E. FINAL & E. ÜTIL & PERDAS \\
\hline E. MOTRIZ & 5.234 & 4.370 & 864 & 83 \\
C. PROCESSO & 1.204 & 1.174 & 30 & 96 \\
AQ DIRETO & 2.131 & 1.109 & 1.022 & 52 \\
ILUMINAÇA & 2.108 & 256 & 1.852 & 12 \\
ELETROQUIMICA & 393 & 156 & 237 & 40 \\
OUTRAS & 224 & 224 & 0 & - \\
TOTAL & 11.294 & 7.289 & 4.005 & 65 \\
\hline
\end{tabular}

A definição da quantidade de perdas observadas num dado sistema depende do que se arbitrar como suas fronteiras. Os critérios utilizados no BEU definem fronteiras das quais resultam, em muitos casos, perdas substancialmente menores do que as que efetivamente ocorrem na entrega do que chamarlamos de servico energético. Por exemplo, no caso de refrigeradores $e$ ar condicionado, o BEU, por classificar estes equipamentos na categoria de força motriz, indica altos niveis de eficiência $(\eta=95)$ e, conseqüentemente, pequenas perdas. Na realida. de, estas são muito maiores, uma vez que a eficiência total do processo abrange, não só a eficiência do motor do equipamento, como a do compressor e a do ciclo de calor.

Continuando com o exemplo do refrigerador, verifica-se que as exigéncias por energia útil podem, também, ser reduzidas, através de utilização de maior espessura de isolamento, o que reduziria a carga térmica, solicitando menos trabalho por parte do equipamento. No caso do ar condicionado, o mesmo ocorreria por exemplo, como conseqüência quer de fenestração diferente, usa de "brise-soleil", ou roorientação do cómodo.

\section{Nota 3}

Os processos ligados à oferta de energia, como quaisquer outros processos de produção oferecem oportunidades de conservaçכ̄o onde se pode tentar a redução de perdas, neste caso, nos processos que vão desde a produção primária de energéticos, sua transformaç5̃o em formas secundárias, até os veículos de transmissão e distribuiçăo, e que permitem colocar a energia em sua forma final à disposição do consumidor. Essa questão não será abordada neste trabalho.

\section{Nota 4}

O grau de flexibilidade na substituição entre insumos é dado pelo valor das elasticidades, ilustradas no gráfico. Estas vão determinar, co. mo conseqüència do aumento de preços, em que proporção se dá a re. dução da quantidade de energia utilizada com relação ao aumento de outros insumos, o grau em que é afetado o nivel da produção, bem como a part icipaçæo dos insumos, em valor, na produçăo.

A isoquanta que apresenta elasticidade igual a zero indica que os insumos estão combinados em proporç̋es fixas, fora das quais sua uri. lizaçäo é sempre ineficiente, não havendo, portanto, margem para substituição entre os mesmos. Na eventualidade de um aumento dos preços de energia, o seu consumo näo diminui e o seu cus to mais alto é absorvido através de uma queda na produção que, al sim, provoca uma queda correspondente no consumo de energia, embora a participação, em valor, da energia na produção fique mais alta. 
No outro extremo se situa a isoquanta da elasticidade infinita, uma impossibilidade técnica, uma vez que implicaria na utilizaçăo de máquinas sem energia, ou na de energia sem máquinas.

A isoquanta unitária indica a situação em que, diante de um au. mento de preços, se observa uma redução proporcional no consumo de energia e um aumento proporcional no consumo dos demais insumos. O nivel da produção, neste caso, manter-se-ia igual, bem como a participação em valor, da energia na produção.

A situaçāo na qual a isoquanta se situa entre 1 e infinito indica que, com o aumento de preços, haveria redução mais do que proporclorıal no consumo de energia e na sua participaçăo na produção e, por outro lado, aumento mais do que proporcional no consumo de outros insumos e nas suas respectivas participaçōes. $O$ nivel da produç̃̃o se manteria igual.

A situaç̃o empiricamente mais encontrada é aquela que situa as elasticidades en tre 0 e 1 . Neste caso, um aumento de precos traduz-se numa redução de consumo e do valor da participaça da energia na produção menos do que proporcional ao aumento de preços. A produção final sobre redução.

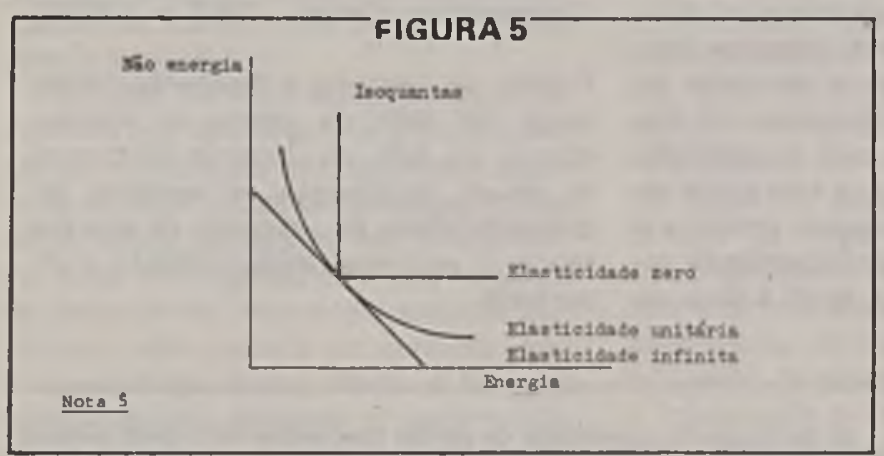

\section{Nota 5}

No tocante à elasticidade-preço da demanda por energia é interessante citar as conclusōes de uma resenha de artigos sobre o tema (Taylor 1977).

"Parece-me que há indícios suficientes para se afirmar que o preco da energia é importante na determinação da quantidade de energis que consumida. De fato, năo se tem conhecimento de qualquer estu. do sobre a demanda de energia que se possa considerar digno de crédi to em termos de especificaçăo e da maneira como o preço (ou preços) é definido, que não apresente como resultado uma elasticidade-preço de demanda de uma certa magnitude e importáncia estatística. O con. sumo de energia não é simplesmente uma questão de renda e forma de viver".

\section{Nota 6}

Quando, após a introdução de uma inovação tecnologica, a função de produção apresenta uma estrutura de utilização dos diversos insumos, idêntica à anteriormente existente, obcerva-se, em termos do gráfico (para uma mesma relação de preços), um deslocamen to da isoquanta de 1 para 2. Ou seja, a proporça na qual os insumos são combinados mentém-se igual, caindo a relaç̃o global insumo/produto, o que implica em deslocamento do ponto a, para o b. A inovação pode, no entanto, apresentar-se mais favorável a qualquer um dos insumos. Ao conter, por exemplo, um viés mais favorável à conservação de recursos energéticos, ter-se-ia, em termos do gráfico, um deslocamento da isoquanta de 1 para 3, e do ponto a para o ponto c, ou seja, consome-se menos de ambos os recursos, mas proporcionalmente menos do insumo energia, e mais do nāo-energia.

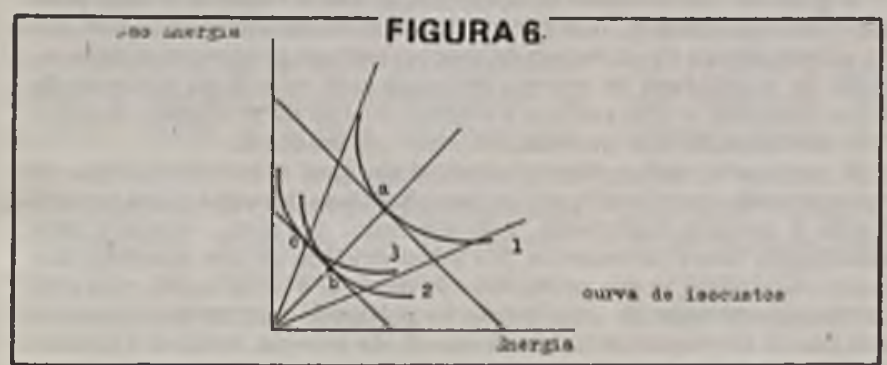

\section{Nota 7}

Nesta economia de minimizaçơes e maximizaçōes, se a última unidade monetária gasta nos diversos insumos, bem como os preços obtidos pelos produtos refletirem as verdadeiras oportunidades económicas de utilização, ter-se-á, então, uma otimização dos mercados de energia a nivel e entre consumidores e fornecedores.

\section{Nota 8}

O gráfico (Marshall e Ruegg, 1980) ilustra a afirmação. O formato das curvas incorpora alguns dos pressupostos usuais na análise microeconômica, tais como: custos marginais crescentes e beneffcios marginais decrescentes, o que confere às correspondentes curvas de custos e beneficios totais suas formas especificas.

A maximização da diferenca entre benefícios e custos e conservaçāo ocorre no ponto $A$, onde interceptam-se as curvas de custos e beneficios marginais. Neste ponto, são iguais os custos e benefícios de se adicionar mais uma unidade de conservaçăo e são mais distantes as curvas de beneflcios e custos totais.
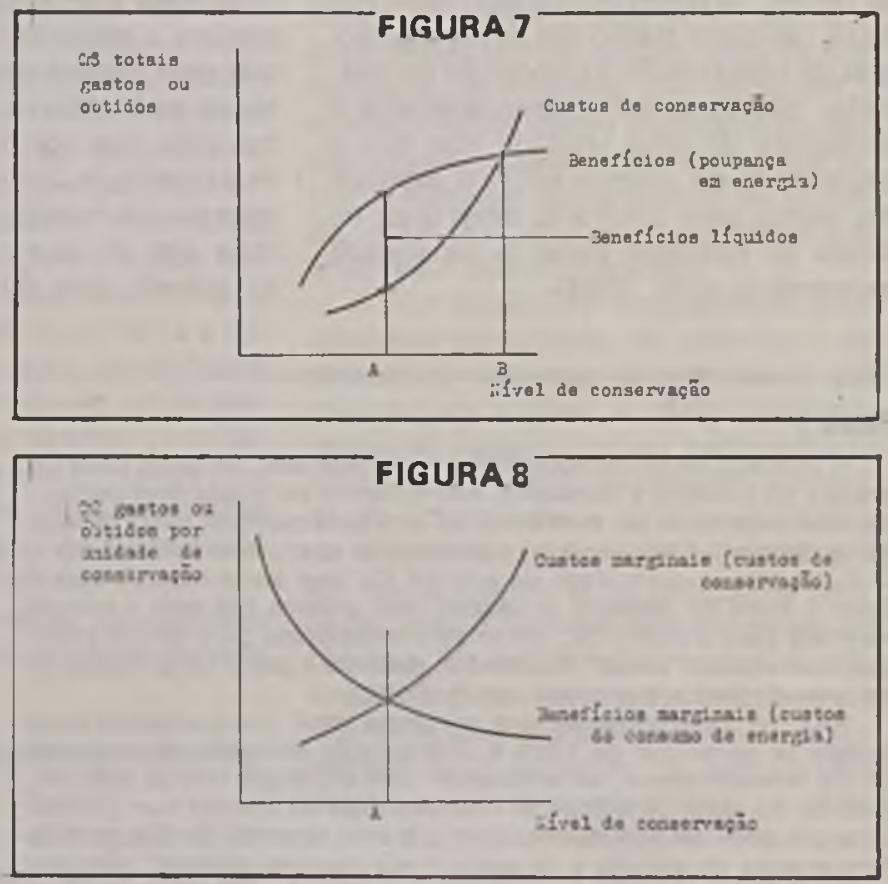

Nota 9

O racioc/nio feito aqui constitue uma ampliaçăo e generalização de exemplo numérico relatado em Nirtshafter, 1985.

\section{Nota 10}

A situação é ilustrada pelo gráfico, onde, em relação ao custo marginal privado de $P_{1}$, o consumo se situa em $Q_{p}$, acima do $n$ ivel ótimo Qs

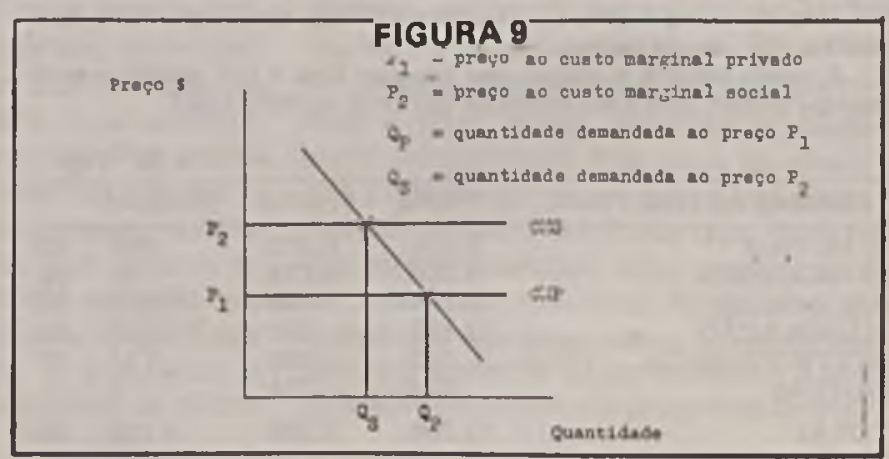




\section{BIBLIOGRAFIA}

AFME, Agence Française pour la Maftrise de l'Energie, Les Aides aux Entreprises Industrielles, s.d.

Berry, L e Hirst, E.. 'Evaluating Utility Residential Energy Conserva. tion Programmes: and Overview of an EPRI Workshop"., em Energy Policy. Março 1983.

California Energy Commission, California's Appliance Standards: An Historical Review, Analysis and Recommendations. California Energy Commission, Sacramento, CA, 1983.

The Energy Conservation Center - Japan, Racionalizaçåo e Conservação da E nergia no Japão, Fevereiro 1984.

Griffin, J.M., Energy Conservation in the OEDC, 1980 to 2000. Cambridge: Ballinger, 1979.

Griffin, J.M. e Steele, H.B., Energy Economics and Policy. New York. Academic Press, 1980.

Hausman, J.A. e Joskow, P.L. "Evaluating the Costs and Benefits of Appliance Efficiency Standards", em American Economic Association Papers and Proceedings, vol. $72-n$ ? 2. s.d

Hicks J.R. , The Theory of Wages. London: Macmillan, 1963.

International Business Week. "Are Utilities Obsolete?" 21-5-1984.

Lebel, P. G., Energy Economics and Technology. Baltimore: Johns Hopkins University Press, 1982.

Lovins, Amory B., Saving Gigabucks With Megawatts. Relatorio para o Painel "energy Conservation: a Cornerstone of National Independence". 19th Annual Convention, National Association of Regulatory Utility Commissioners. Los Angeles, Novembro 1984.

Marshall, H.E. e Ruegg R.T., "Principles of Economics Applied to Investments in Energy and Solar Energy Systems", em Kreith, F. e West, R.E., Economics of Solar Energy and Conservation Systems, vol. 1, Boca Raton: CRC Press inc, 1980.

Musasinghe, M., "Third World Energy Policies", em Energy Policy, Março 1983.

OECD, Energy Conservation in the International Energy Agency: 1976 Review. Paris, 1976.

Sanghvi, Arun P., "Least-Cost Energy Strategies for Power System Ex. pansion". em Energy Policy, Março 1984.

Sawyer, Stephen W. "Federal-State Conservation Programmes", em Energy Policy, Abril 1985.

Serra, M.V. e Pagy, A. A Penetração no Brasil das Eletrotecnologias de Ponta: Adoção da Eletrotermia. LIGHT. Informaçao Técnica $001 /$ 84. Janeiro de 1984.

Stern, P. C. Berry, L. G. e Hirst, E., "Residential Conservation Incentives", em Energy Policy, Abril 1985

Taylor L $L .0$. "The Demand for Energy: a Survey of Price and Income Eleticities", in William D. Nordhaus, International Studies of the Demand for Energy. Amsterdam: North Holland Publishing Company. 1977.

Wirtshafter, Robert M. 'Non-Participants in Utility Energy Conservation Programmes", em Energy Policy, Abril 1985.

\section{AGRADECIMENTO}

Agradeço a Luiz Flávio Niemever a leitura cuidadosa e comentada deste trabalho, contribuindo para tornar mais claros vários pontos do mesmo. 